\title{
Historical Trends of Academic Research on the Water Environment in Japan: Evidence from the Academic Literature in the Past 50 Years
}

\author{
Masashi Kuroda ${ }^{1,2, *}{ }^{\mathbb{C}}$, Keishiro Hara ${ }^{2}$, Masashi Takekawa ${ }^{1}$, Michinori Uwasu ${ }^{3}$ and \\ Michihiko Ike ${ }^{1,2}$ \\ 1 Division of Sustainable Energy and Environmental Engineering, Graduate School of Engineering, \\ Osaka University, Osaka 565-0871, Japan; takekawa33@gmail.com (M.T.); ike@see.eng.osaka-u.ac.jp (M.I.) \\ 2 Center for Open Innovation Research and Education, Graduate School of Engineering, Osaka University, \\ Osaka 565-0871, Japan; hara@ceids.osaka-u.ac.jp \\ 3 Center for the Study of Co* Design, Osaka University, Osaka 560-0043, Japan; uwasu@ceids.osaka-u.ac.jp \\ * Correspondence: kuroda@see.eng.osaka-u.ac.jp; Tel.: +81-6-6879-7673
}

Received: 21 September 2018; Accepted: 13 October 2018; Published: 16 October 2018

\begin{abstract}
This paper analyzes historical trends of academic research on the water environment in Japan over the past 50 years in relation to societal circumstances by looking into 1470 articles published in a Japanese domestic journal during 1961-2010. We examined three components of the individual articles to substantiate the trends including "Visions", "Target Water", and "Objects". The database of these components was first constructed, and then statistically analyzed. Principal components analyses revealed two historical turning points of the research trends, in 1970 and in the mid-1990s, showing first a clear transition of the main concern from industrial pollution to eutrophication, and later, a transition to global environmental issues. We also demonstrate that Visions and Target Water gradually diversified during the past 50 years, indicating that although the research activity in the early periods focused on serious pollution issues, more recently, the scope of water environmental studies expanded to various other issues along with the improvement in the quality of the water environment. We argue that academic research activity in Japan was conducted in close association with public concern and global movements in a timely and sensitive manner. Such knowledge could also provide implications to other nations facing serious water pollution.
\end{abstract}

Keywords: water environment; literature survey; academic research trend; statistical analysis

\section{Introduction}

Water is essential for all life on earth, and the most important basis for all human activities. Japan has maintained a high-quality water environment in recent years, and most observation points met health-related environmental standards [1]. However, in the middle of the 20th century, Japan suffered from severe water pollution, which was due to the rapid economic growth during and following its recovery from World War II [2,3]. Heavy metal pollution occurred in the 1950s and directly threatened public health. In particular, Itai-itai disease (cadmium poisoning) and Minamata disease (mercury poisoning) are well-known tragedies caused by that pollution [4,5]. In the 1970s and 1980s, eutrophication (excess bloom of algae) in closed bodies of water spoiled the water environment by bringing health hazards and economic damage [6]. Developing countries are currently suffering from similar problems as economic development takes place. Indeed, empirical studies have revealed that such types of water pollution are associated with the level of economic development and other societal background factors, such as urbanization and industrialization [7-9]. Therefore, understanding how Japan historically recovered from such a situation would provide lessons for and insights into 
sustainable management of the water environment during each stage of socioeconomic development, providing essential implications to economically developing countries just suffering from serious water pollutions.

So far, qualitative studies on the environmental history of Japan have been abundant [10-15]. Matsuo [14] simply summarized the environmental history of Japan by referring to several statistical data sources. It was pointed out that the rapid economic growth since the mid-1950s was accompanied by an increase in both the qualitative and quantitative environmental impact of wastewater, which caused serious pollution issues. Kataoka [15] reviewed the succession of water quality management in Japan, especially from a legislative perspective. Kataoka [15] also argued that the scope of water quality management has historically expanded from pollution control in the early period to water environmental management including the many challenges of the water environment, such as ecosystem conservation and adaptation to climate change impacts. On the other hand, quantitative studies related to the history of environmental issues are still very limited [16-21]. For example, Popp [18] analyzed innovation in environmental technology using patent data in the USA, Japan, and Germany, and found that inventors respond to domestic regulatory pressures, but not foreign regulatory pressures. In two case studies, Yabar et al. [20] revealed that in Japan, regulations induced new technological developments to reduce the emissions of dioxins from incinerators and the recycling of home electric appliances. They highlighted the influence of policies, such as regulations, on technological innovations. Although there is no doubt that these studies shed light on the activities of the industrial sector in response to the environmental issues, to the best of our knowledge, no quantitative studies have addressed the history of academic activities related to water environmental issues in Japan.

We hypothesized that academic papers published in relevant journals could help us to systematically develop an understanding of the historical academic activity relating to how water-related issues have been dealt with in each stage of economic development and social change, because these articles contain an enormous volume of information about the logical links between the societal background and the academic and industrial research activities. More specifically, we argue that delving into academic papers can provide information on what the primary water challenges have been at different times, how research activities attempted to cope with such challenges, and a historical view of the main visions for and scope of research activities. These points could be examined in relation to the social background and societal needs in Japan by referring to academic papers published in relevant journals over the relevant decades.

In this study, we look into the archives of a specific Japanese academic journal in order to carry out a substantiated analysis on the past process of the recovery from environmental issue in relation to the societal development in Japan. Indeed, there are large number of papers historically published in journals reflecting the long history of coping with water-related issues, as addressed earlier, and abundant lessons and relevant experiences in Japan. We comprehensively surveyed the academic papers published in this journal during the years 1961 to 2010 in order to construct a database containing information about the research targets and the vision of each paper. The research trends were determined by statistical analyses of this database, and we then examined the association between the identified trend and the societal background; we paid particular attention to each stage of water environmental issues and the relevant regulations during this time period.

The remainder of this paper is structured as follows. The next section explains the methodology we used for data collection and the statistical analyses. The third section presents our results, including the primary data obtained by statistical analyses, an overview of the societal background in association the academic activity. The fourth section discusses a comparison of our findings with relevant studies and obtained implications. The fifth section presents the conclusion. 


\section{Materials and Methods}

\subsection{Survey of Previous Studies Related to Academic Activity}

Various previous reports used a database of patents to analyze the association between environmental innovation and relevant laws [18,20,22-24]; however, few reports analyzed academic research activity, which could be partially due to the lack of an established methodology. Some of the reports used public databases, such as the Science Citation Index (SCI), for the analysis of academic activity. For example, Wang et al. [25] used bibliometric techniques with the SCI to analyze 11,854 articles published in Water Research from 1967 to 2008; they evaluated the publication performance of countries and institutes and found that adsorption was the most popular technique. Hu et al. [26] analyzed the trend in studies published during the years 1991 to 2007 that were related to lead in drinking water; the SCI was used to categorize studies by research field, such as environmental sciences, toxicology, analytical chemistry, and civil engineering. They found that the number of annual publications increased during two periods, namely from 1992 to 1997 and from 2005 to 2007. Using a public database is advantageous in terms of accessibility to numerous datasets and availability to all researchers. Information can be extracted by entering single keywords related to environmental issues. However, the true intentions of the authors cannot be interpreted. In particular, it cannot be determined which environmental issues each author targeted; this is because their intentions are generally found by considering the context, not just through a single keyword. A systematic review method employed by Klewitz and Hansen [27], which was a combination of quantitative analysis of publications by consulting public databases with qualitative analysis of selected articles for detailed interpretation, is a good example to complement the deficiency in the analysis using public databases.

Taking the implications from previous studies into account, this study developed a new method using a manual survey of academic papers. Through the manual survey, authors' intentions can be properly comprehended from the contexts of papers; this method is superior to the methods using public databases, and is better suited for the purpose of this study. This method may also have certain limitations; for example, a major concern is that the manual judgments might be biased and might limit the objectivity of the database. To cope with this point, this study tried to exclude individual judgments by using an exhaustive checklist, which was carefully prepared by a preliminary survey of the articles.

\subsection{Academic Papers Surveyed}

To conduct a substantiated analysis of the academic activities toward the past process of the recovery from water environmental issues in Japan, we first set the following four criteria that must be considered for the selection of academic journals surveyed. The source journals should (1) contain publications related to water environmental issues in Japan; (2) contain original articles (peer-reviewed articles) on the basis of voluntary submission by academic researchers; (3) accept a wide range of topics relevant to water environmental issues and (4) publish relevant papers between the period from the 1960s to 2000s during which socioeconomic conditions and associated water problems changed dynamically. For criterion (1), Japanese domestic journals are more suitable than international journals because most papers published in Japanese domestic journals are created by Japanese researchers or research groups. Addressing criterion (2), Japanese domestic journals in Table 1 were listed and considered as candidates for the analysis. Considering criterion (3), the journals Yosui-to-haisui (Journal of Water and Waste) and Suishitsuodaku-kenkyu/Nihon-mizukankyo-gakkaishi (Japan Journal of Water Pollution Research/Journal of Japan Society on Water Environment) have received articles on a wide range of research, whereas Nihon-mizusyoriseibutsu-gakkaishi (Japanese Journal of Water Treatment Biology) and Suimon-mizushigen-gakkaishi (Journal of Japan Society of Hydrology and Water Resource) have published articles on relatively specific fields of study. With respect to criterion (4), only Yosui-to-haisui covers the period from the 1960s to 2000s. Putting all the criteria together, it was considered that the journal 
Yosui-to-haisui best represents the history of academic research in Japan during a long period with the lowest bias arising from the journal scope.

Table 1. Candidates of journals for further analysis.

\begin{tabular}{llc}
\hline \multicolumn{1}{c}{ Title in Japanese (in English) } & \multicolumn{1}{c}{ Journal Scope } & Publication Period \\
\hline Yosui-to-haisui (Journal of Water and Waste) & $\begin{array}{l}\text { Water/wastewater treatment, water } \\
\text { environment conservation }\end{array}$ & 1959-present \\
\hline $\begin{array}{l}\text { Nihon-mizusyoriseibutsu-gakkaishi (Japanese } \\
\text { Journal of Water Treatment Biology) }\end{array}$ & $\begin{array}{l}\text { Biology, ecology, biotechnology related } \\
\text { to water/wastewater treatment }\end{array}$ & 1964-present \\
\hline $\begin{array}{l}\text { Suishitsuodaku-kenkyu (Japan Journal of Water } \\
\text { Pollution Research)* }\end{array}$ & $\begin{array}{l}\text { Water environment conservation, } \\
\text { water/wastewater treatment, hydrology }\end{array}$ & 1978-1991 \\
\hline $\begin{array}{l}\text { Nihon-mizukankyo-gakkaishi (Journal of Japan } \\
\text { Society on Water Environment)* }\end{array}$ & $\begin{array}{l}\text { Water environment conservation, } \\
\text { water/wastewater treatment }\end{array}$ & 1992-present \\
\hline $\begin{array}{l}\text { Suimon-mizushigen-gakkaishi (Journal of Japan } \\
\text { Society of Hydrology and Water Resource) }\end{array}$ & Hydrology & 1988-present \\
\hline
\end{tabular}

Note: * The journal Suishitsuodaku-kenkyu is a predecessor of the journal Nihon-mizukankyo-gakkaishi.

Consequently, academic research articles published in Yousui-to-haisui during the period from 1961 to 2010 were selected for this study.

The articles surveyed were peer-reviewed, full-length, regular scientific papers. Invited research papers for special issues, notes, reviews, and reports were omitted from this analysis; we did this so that we were focused on actual trends in research, and so that any bias arising from the intention of journal editors was eliminated. Research papers obviously not related to water were also omitted. In total, 1470 papers were selected for this analysis.

\subsection{Construction of the Database}

The articles were surveyed to construct the database. In the first stage of the survey, the year of publication and underlying research background for each article was checked against a preset check sheet. The underlying research background was assumed to consist of three components: "Visions", "Target Water" and "Objects". Visions denotes the mid- and long-term social goals that the papers implicitly or explicitly stated. That is, this directly represents the issues that the study addressed. The classes and their descriptions of Visions are listed in Table 2. For example, an article dealing with industrial wastewater treatment falls into the class Industry-related (V1), while one that deals with sewage treatment falls into the class Public facilities-related (V2). Target Water indicates the type of water that the research articles investigated, e.g., Municipal water (W1), Sewage (W4), and Industrial wastewater (W7) (Table 3). Objects present target substances, organisms, or water itself that each article analyzes. The classes and their descriptions of Objects are listed in Table 4. For example, $\mathrm{pH}$ falls into the class Basic Properties of Water, and Hg falls into the class Metals. Target Water and Objects facilitate tangible interpretations of the issues targeted by the articles. The classes in the three components for the paper categorizing were objectively selected. For example, items of the Japanese environmental standards and the keywords in the series of white papers by the Ministry of the Environment of Japan [10-12] were employed to develop the classes in three components. Articles that did not meet the preset classes were categorized as "Others", and their details were described on the check sheet in the first stage of the survey. Then, in order to include as much relevant content as possible in the check sheet used for the second stage of the survey, the classes on the check sheet were reconsidered, and carefully integrated the articles classified as Others in the first stage of the survey into the specific classes. In this second stage, three components of each article were checked against the exhaustive check sheet listing the renewed classes. Then, constructed database was subjected to the statistical analyses. 
Table 2. Classes in the database "Visions".

\begin{tabular}{ll}
\hline \multicolumn{1}{c}{ Classes } & \multicolumn{1}{c}{ Description } \\
\hline V1: Industry-Related & $\begin{array}{l}\text { Technological development, water resource reservation, cost-cutting, } \\
\text { effective utilization of water in industrial and agricultural field }\end{array}$ \\
\hline V2: Public Facilities-Related & $\begin{array}{l}\text { Technological development, cost-cutting, effective utilization of } \\
\text { water in municipal water and wastewater treatment service }\end{array}$ \\
\hline V3: Water Environment Preservation & $\begin{array}{l}\text { Prevention of pollution and eutrophication of water environment } \\
\text { (river, lake, sea, etc.) }\end{array}$ \\
\hline V4: Drinking Water Quality & $\begin{array}{l}\text { Reservation of water resource, water safety, water flavor for public } \\
\text { water supply }\end{array}$ \\
\hline V5: Waste Reduction & Reduction of volume of waste materials \\
\hline V6: Energy-Saving & $\begin{array}{l}\text { Energy-saving, energy-generation } \\
\text { (articles related to low carbon were excluded) }\end{array}$ \\
\hline V7: Low-Carbon & Energy-saving, energy-generation in the context of low carbon \\
\hline V8: Ecosystem & Preservation of wildlife and ecology of wildlife \\
\hline V9: Resource Recycling & $\begin{array}{l}\text { Reuse and recycle of materials } \\
\text { (articles related to recycling as energy were excluded) }\end{array}$ \\
\hline V10: Others & Articles contain no specified “Visions" classified in V1-V9. \\
\hline
\end{tabular}

Table 3. Classes in the database "Target Water".

\begin{tabular}{l}
\multicolumn{1}{c}{ Classes } \\
\hline W1: Municipal Water \\
W2: Industrial and Agricultural Water Supply \\
W3: Public Swimming Pool and Bath \\
W4: Sewage \\
W5: Greywater \\
W6: Human Waste \\
W7: Industrial Wastewater \\
W8: Animal Wastewater \\
W9: Agricultural Wastewater \\
W10: Food Industrial Wastewater \\
W11: Landfill Leachate \\
W12: Groundwater \\
W13: Lake Water \\
W14: River Water \\
W15: Sea Water \\
W16: Mudflat \\
W17: Sludge \\
W18: Others
\end{tabular}

Table 4. Classes in the database "Objects".

\begin{tabular}{ll}
\hline \multicolumn{1}{c}{ Classes } & \multicolumn{1}{c}{ Description } \\
\hline O1: Basic Properties of Water & $\mathrm{pH}$, color, $\mathrm{SS}, \mathrm{BOD}, \mathrm{COD}$, chloride, flavor, etc. \\
\hline O2: Metals & $\mathrm{Hg}, \mathrm{Cd}, \mathrm{Pb}, \mathrm{Cr}, \mathrm{As}, \mathrm{Se}, \mathrm{Cu}, \mathrm{Zn}, \mathrm{Fe}, \mathrm{Mn}$, other metals \\
\hline O3: Inorganic Matter & $\mathrm{N}, \mathrm{P}, \mathrm{F}, \mathrm{B}, \mathrm{S}$ \\
\hline & $\begin{array}{l}\text { Cyanide, organic-P, PCB, trichloroethylene, tetrachloroethylene, } \\
\text { dichloromethane, carbon tetrachloride, 1,2-dichloroethane, } \\
\text { 1,1-dichloroethylene, cis-1,2-dichloroethylene, 1,1,1-trichloroethane, } \\
\text { 1,1,2-trichloroethane, 1,3-dichloropropene, benzene, thiuram, simazine, } \\
\text { thiobencarb, etc. }\end{array}$ \\
\hline O5: Organic Matter & BOD, COD, TOC, oil, sediment, etc. \\
\hline O6: Organisms & Aquatic life, algae, microorganism, virus \\
\hline O7: Waste Materials & Sludge, etc. \\
\hline O8: Water Flow & Water flow, volume of water \\
\hline O9: Others & Articles contain no specified “Objects” classified in O1-O8. \\
\hline
\end{tabular}




\subsection{Statistical Analyses}

To clarify the trends in research over the past 50 years from the multivariate database, three statistical analyses were employed. The first approach was principal component analysis (PCA; [28]) coupled with biplot [29], which graphically shows the loadings of the principal components. With this method, it is possible to characterize the research articles in each time period with respect to Visions, Target Water, and Objects.

The diversity of the research components in different periods was investigated using Shannon's diversity index $H^{\prime}$ [30], which is generally used in the fields of biology and ecology to measure the diversity of species, but is also used to evaluate the diversity of the components in the field similar to this study [21]. The calculation is based on the total number of species (corresponding to the research components in our study) and the population of each species (corresponding to the number of articles of a particular research type) within a particular spatial boundary (time period). In the context of this study, the larger the value of the index, the more diverse are the article characteristics in a particular time period.

Factors contributing to the diversifications of Visions, Target Water, and Objects were estimated by the Pearson correlation, which is the third statistical approach used in this study. Correlation coefficients and $p$ values between the transitions of the diversity indices and the number of each class in the corresponding category were calculated for five-year periods. It was considered that, where the diversity index gradually increased over a given period, a class exhibiting a positive correlation coefficient could contribute to the diversification of the corresponding components.

All statistical analyses were implemented using the freeware PAST version 3.0 [31] (http:/ / folk.uio.no/ohammer/past/).

\section{Results}

\subsection{Overview of Constructed Database}

The database was constructed through the survey of 1470 peer-reviewed regular papers published in the journal Yosui-to-haisui. The annual number of articles in the database was shown in Figure 1. The number of articles published in 1961, 1968, 1969, and 1985 were limited, because most volumes in these years were published as special issues that did not include peer-reviewed original papers. The Target Water, Visions, and Objects of the articles were surveyed and categorized into the classes shown in Tables 2-4. The constructed database was shown in Table S1. To avoid misleading results derived from a small sample size, the 5-years subtotals, shown in Figures 2-4, was employed for further study. The minimum sample size of the 5-year subtotals was 102 papers during both 1966-1970 and 2006-2010.

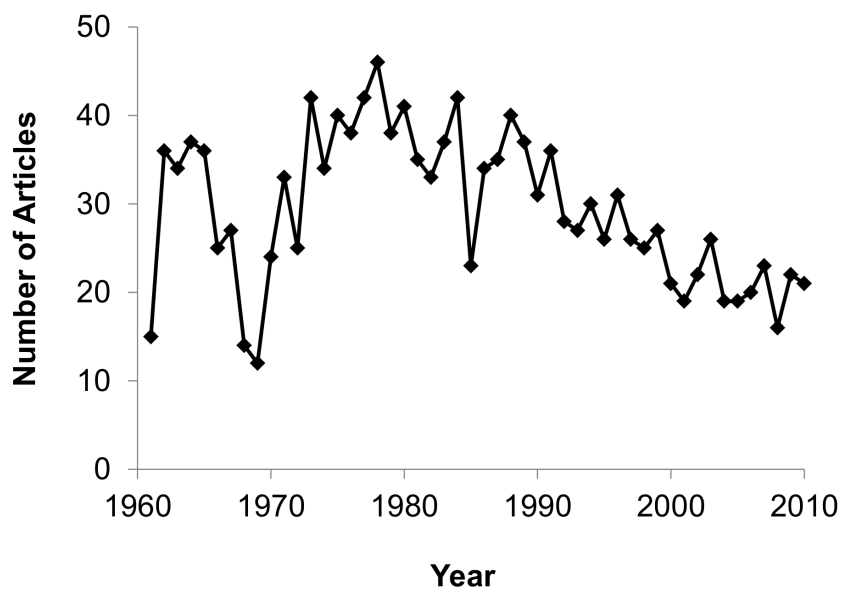

Figure 1. Annual number of articles in the database. 


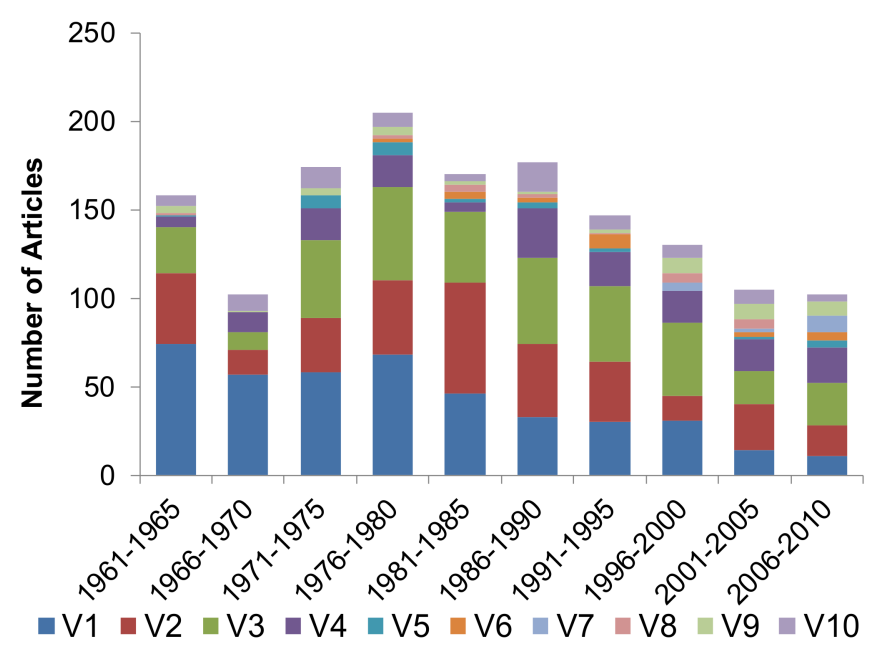

Figure 2. Number and composition of articles categorized in "Visions", denoted as "V".

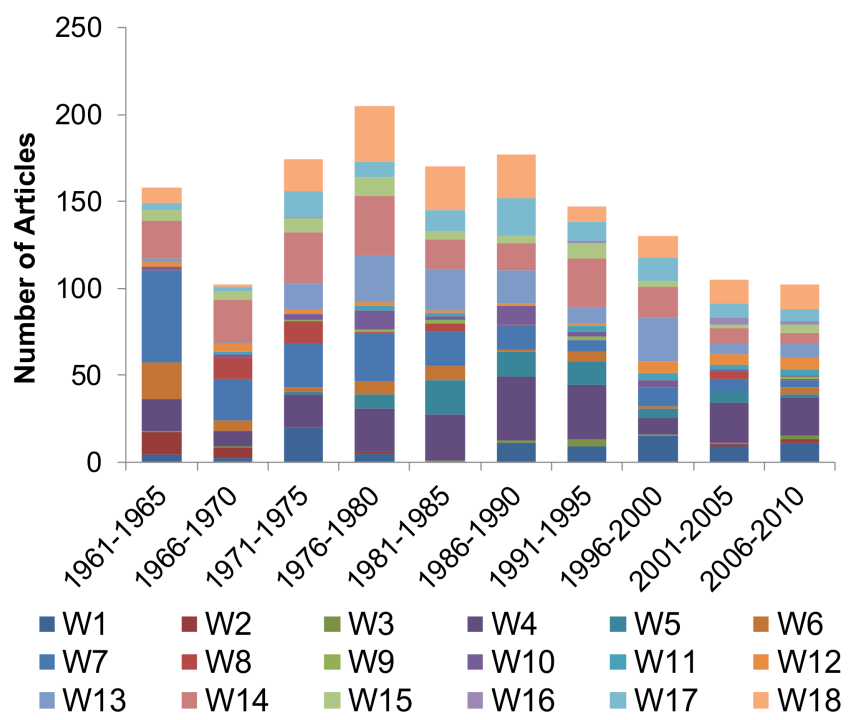

Figure 3. Number and composition of articles categorized in "Target Water", denoted as "W".

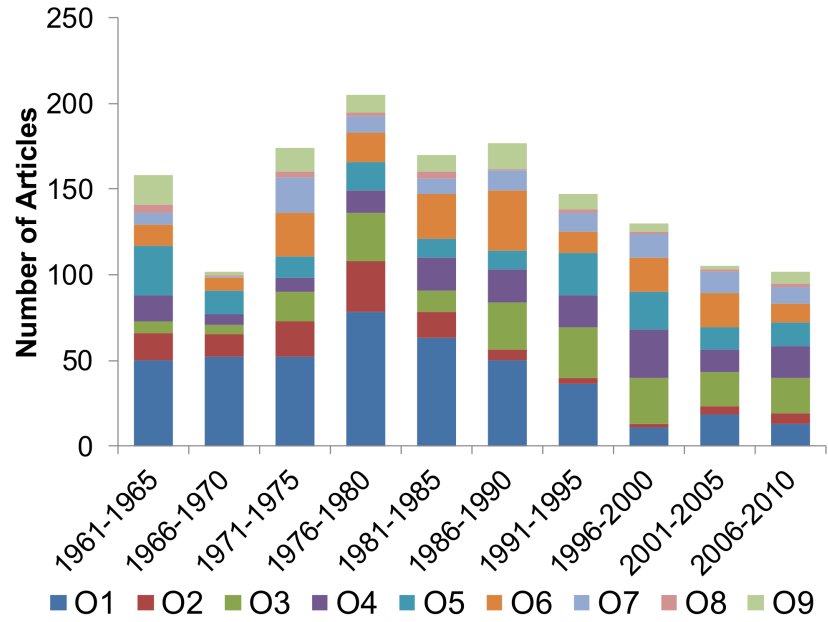

Figure 4. Number and composition of articles categorized in "Objects", denoted as "O". 


\subsection{PCA Based on Classes}

PCA was conducted to clarify the trends in research over the past 50 years. A scatter plot of the principal components (PCs) 1 and 2 for the classes in Visions for each 5-year period was shown in Figure 5. The biplot shown as radial lines indicated that the articles during the period 1961-1990 were mainly characterized by Industry-Related and Public Facilities-Related visions. Articles during the period 1971-1995 were characterized by Water Environment Preservation, Waste Reduction, Others, Drinking Water Quality, and Energy-Saving. Articles during the period 1996-2010 were characterized by Low-Carbon, Ecosystem, and Resource Recycling.

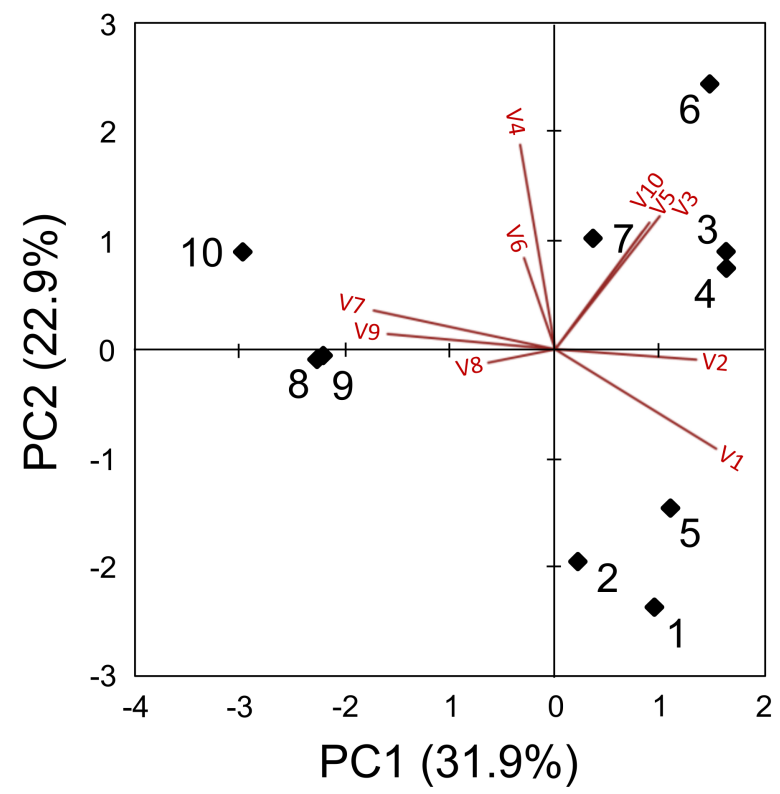

Figure 5. PCA of classes in the category "Visions", denoted as "V". Radial lines indicate the results of the biplot analysis. Diamonds with numbers represent the "Visions" of the articles published during each five-year period; period 1, 1961-1965; period 2, 1966-1970; period 3, 1971-1975; period 4, 1976-1980; period 5, 1981-1985; period 6, 1986-1990; period 7, 1991-1995; period 8, 1996-2000; period 9, 2001-2005; period 10, 2006-2010.

A scatter plot of PC1 and PC2 for the classes categorized in Target Water for each 5-year period was shown in Figure 6. The biplot indicated that the articles during the period 1961-1970 were characterized by Agricultural and Industrial Water Supply, Human Waste, Industrial Wastewater, and Animal Wastewater. During the period 1971-1995, research targets gradually changed from River Water and Sea Water, to Food Industrial Wastewater, Others, Agricultural Wastewater, Lake Water, Sewage, Greywater, and Sludge. Articles during the period 1996-2010 were characterized by Municipal Water, Landfill Leachate, Public Swimming Pool and Bath, Mudflat, and Groundwater. 


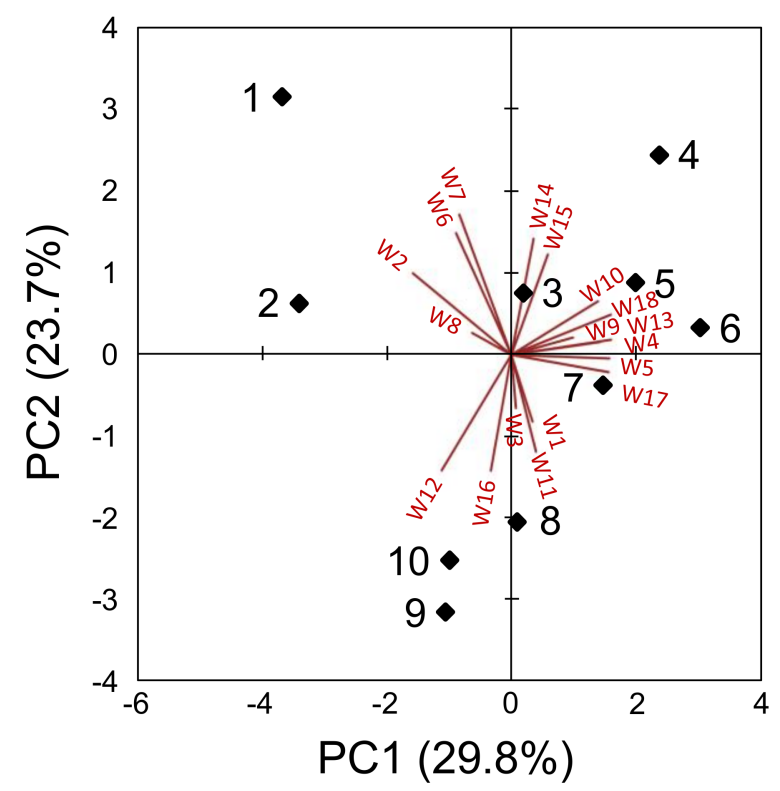

Figure 6. PCA of classes in the category "Target Water", denoted as "W" Radial lines indicate the results of the biplot analysis. Diamonds with numbers represent the "Target Water" of the articles published during each five-year period; period 1, 1961-1965; period 2, 1966-1970; period 3, 1971-1975; period 4, 1976-1980; period 5, 1981-1985; period 6, 1986-1990; period 7, 1991-1995; period 8, 1996-2000; period 9, 2001-2005; period 10, 2006-2010.

A scatter plot of PC1 and PC2 for the classes in Objects for each 5-year period was shown in Figure 7. The biplot indicated that the articles during the period 1961-1965 and 1971-1985 were characterized by Basic Properties of Water, Metals, Water Flow, and Others, although Organic Matter dominated during the periods 1966-1970. The articles are characterized by Inorganic Matter, Organic Chemicals, Organisms, and Waste Materials during the period 1986-2010.

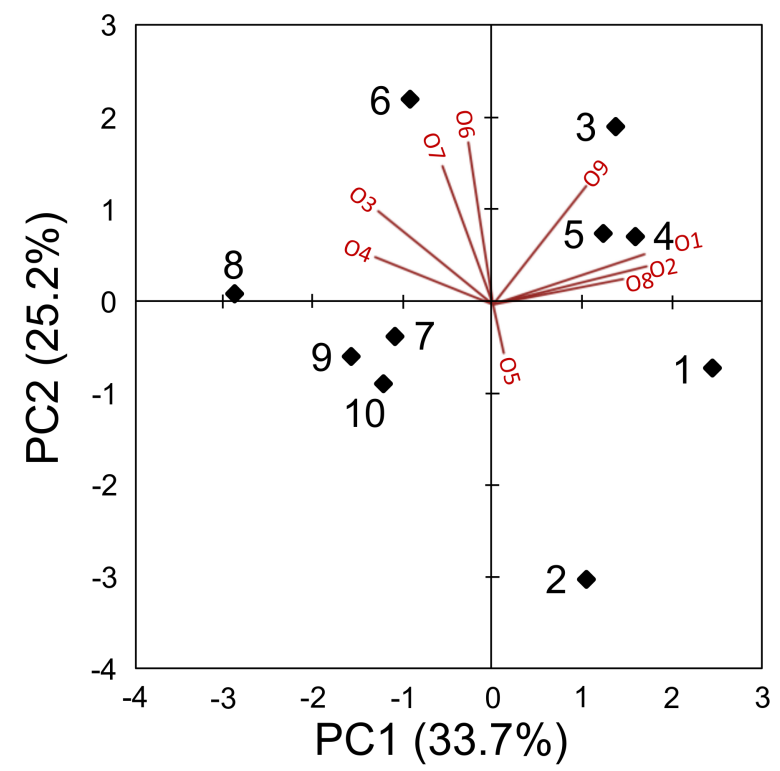

Figure 7. PCA of classes in the category "Objects", denoted as " $\mathrm{O}$ " Radial lines indicate the results of the biplot analysis. Diamonds with numbers represent the "Objects" of the articles published during each five-year period; period 1, 1961-1965; period 2, 1966-1970; period 3, 1971-1975; period 4, 1976-1980; period 5, 1981-1985; period 6, 1986-1990; period 7, 1991-1995; period 8, 1996-2000; period 9, 2001-2005; period 10, 2006-2010. 


\subsection{Correlation between Academic Research Activities and Societal Events}

Based on the results of the PCA, the history of Japanese water environment over the past 50 years can be divided into three periods: Period I (1961-1970), period II (1971-1995), and period III (1996-2010), as shown in Table 5. In period I, many of the articles dealt with industry, such as those classified as Industry-Related (Figure 5), Industrial and Agricultural Water Supply, or Industrial Wastewater (Figure 6); this is thought to reflect the period of high economic growth. After recovering from the damage of World War II, Japan achieved rapid development during the 1960s by giving priority to economic activities; this caused severe environmental pollution [13]. Minamata disease and Itai-itai disease occurred in the 1950s, and these were the result of severe industrial pollution [4,5]. These tragedies underscored the toxicities of heavy metals in Japan. It can be clearly seen in Figure 7 that Metals were the main research targets during the period 1961-1965 and 1971-1985. Reflecting the growing public call for the prevention of industrial pollution, the following laws were enacted: The Basic Law for Environmental Pollution Control (1967); the Water Pollution Control Law and the Law Relating to the Prevention of Marine Pollution and Maritime Disasters at the 64th Diet (1970, [2]). Related academic activity was conducted even before the relevant laws were enacted, suggesting that this academic activity reflected strong public concern about industrial pollution during the era of the rapid economic growth.

Table 5. Three periods characterized by the Visions of academic activities.

\begin{tabular}{|c|c|c|c|}
\hline Periods & $\begin{array}{c}\text { Visions of Academic } \\
\text { Activities }\end{array}$ & Relevant Laws and Conventions & Keywords \\
\hline I: 1961-1970 & $\begin{array}{c}\text { Industry-related, } \\
\text { Public facilities-related }\end{array}$ & Water Pollution Control Law (1970) & $\begin{array}{l}\text { Economic growth, } \\
\text { Industrial Pollution, } \\
\text { Heavy metal }\end{array}$ \\
\hline II: 1971-1995 & $\begin{array}{c}\text { Water Environment } \\
\text { Preservation, } \\
\text { Waste Reduction, } \\
\text { Drinking Water } \\
\text { Quality, Energy Saving }\end{array}$ & $\begin{array}{l}\text { Act on Special measures for } \\
\text { Environmental Conservation of the } \\
\text { Seto Inland Sea (1973) } \\
\text { Act on Special measures for Water } \\
\text { Quality Conservation of Lakes and } \\
\text { Ponds (1984) }\end{array}$ & $\begin{array}{l}\text { Eutrophication, } \\
\text { Pollution from civil life }\end{array}$ \\
\hline III: 1996-2010 & $\begin{array}{c}\text { Low Carbon, } \\
\text { Ecosystem, } \\
\text { Resource Recycling }\end{array}$ & $\begin{array}{l}\text { United Nations Framework } \\
\text { Convention on Climate Change and } \\
\text { the Convention on Biological } \\
\text { Diversity (1992) } \\
\text { Law Concerning the Promotion of the } \\
\text { Measures to Cope with Global } \\
\text { Warming (1998) } \\
\text { Fundamental Law for Establishing a } \\
\text { Sound Material-Cycle Society (2000) }\end{array}$ & $\begin{array}{l}\text { Reflection of global } \\
\text { environmental issues } \\
\text { in water sector }\end{array}$ \\
\hline
\end{tabular}

Period II can be characterized by Water Environment Preservation, Waste Reduction, Drinking Water Quality, and Energy Saving. In the 1970s, eutrophication in the water became an issue [6], especially in lakes and inland seas, and River Water and Sea Water began to be studied. The Act on Special Measures for Environmental Conservation for the Seto Inland Sea was enacted in 1973 to control the severe pollution there; this is a closed body of water surrounded by many cities and heavy industry. As shown in Figure 7, it was gradually revealed that the causative agent of the eutrophication was nitrogen and phosphorus, which are included in Inorganic Matter; Food Industrial Wastewater, Agricultural Wastewater, Sewage, and Greywater, were considered as possible sources of this pollution (see Figure 6). The reason why Drinking Water Quality became a Vision would be that it was directly affected by the water quality of reservoirs polluted by eutrophication. During the same period, the Act on Special Measures for Water Quality Conservation of Lakes and Ponds (1984) was enacted to specifically control wastewater 
discharge into lakes and ponds. The combination of our analysis and historical facts suggests that during period II, academic activities and laws synchronously contributed to tackle the issues.

The influence of human activities on the environment on the global scale became widely recognized after the United Nations Conference on the Human Environment, which was held in 1972. The United Nations Framework Convention on Climate Change and the Convention on Biological Diversity were adopted at the United Nations Conference on Environment and Development, which was held in 1992 [32]. Reflecting the global trend, studies related to "Low-Carbon", "Ecosystem" and "Resource Recycling" increased during period III (see Figure 5), prior to a series of laws concerning global environmental issues, the Law Concerning the Promotion of the Measures to Cope with Global Warming, established in 1998, and Fundamental Law for Establishing a Sound Material-Cycle Society, established in 2000 [33], being established in Japan.

In general, it was suggested that over the last 50 years in Japan, water-related problems and societal events, including the implementation of policy to deal with such problems, changed with the deepening of scientific understanding of environmental issues as well as the development of public awareness of the environment. Academic activity during this period was conducted in close association with public concerns and global movements, and it was not simply reacting to policies and regulations adopted by the government.

\subsection{Diversity of Articles}

The transition of variability of the Visions, Target Water, and Objects of the articles was evaluated by calculating Shannon's diversity index $H^{\prime}$. The transition of $H^{\prime}$, calculated for each 5-year interval was shown in Figure 8. The indices of Visions and Target Water increased, showing that they diversified, although that of Objects was stable over all 50 years. The correlation between $H^{\prime}$ and the numbers of Visions, Target Water, and Objects of the articles was shown in Table 6. The $H^{\prime}$ index of Visions correlated positively with the number of Resource Recycling, Low-Carbon, and Water Supply and negatively with Industry-related. The indices of Target Water correlated positively with Landfill Leachate and Mudflat and negatively with Industrial Wastewater, Agricultural and Industrial Water Supply, and Human Waste. The index of Objects was positively correlated with Waste Materials.

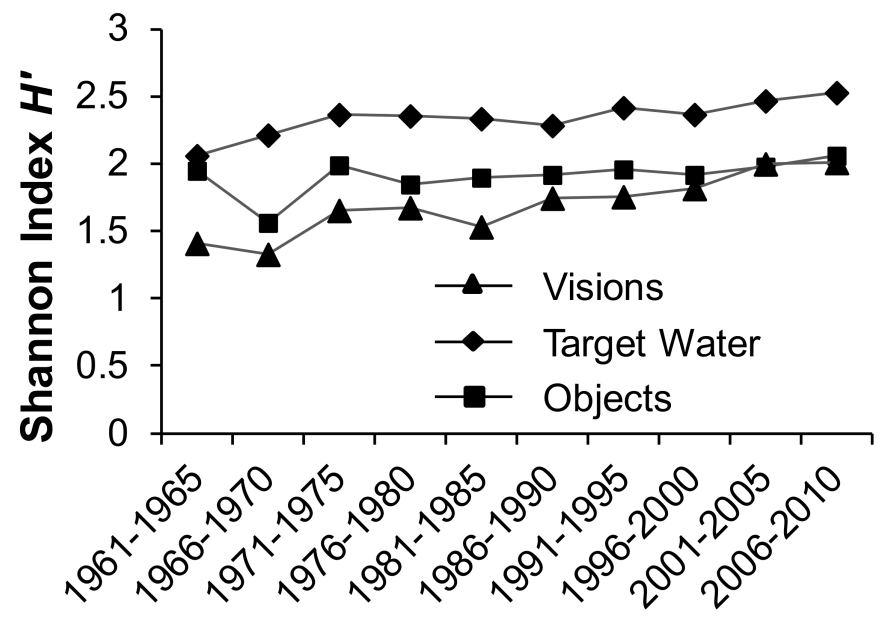

Figure 8. Transition of the diversities of articles based on Shannon's $H^{\prime}$ indices of "Visions", "Target Water", and "Objects" during the years 1961-2010. 
Table 6. Classes correlated with Shannon Indices ${ }^{a}$.

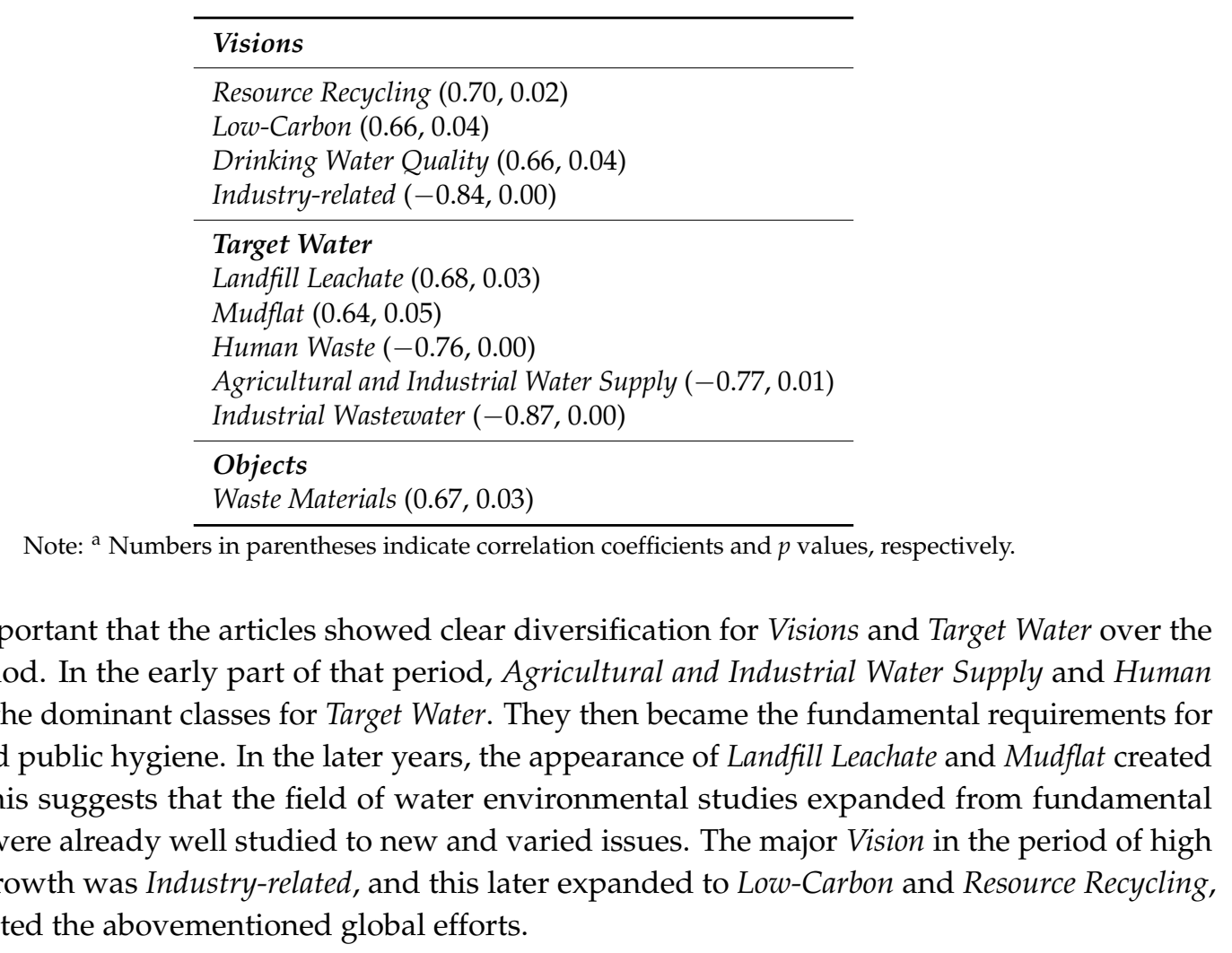

It is important that the articles showed clear diversification for Visions and Target Water over the 50-year period. In the early part of that period, Agricultural and Industrial Water Supply and Human Waste were the dominant classes for Target Water. They then became the fundamental requirements for industry and public hygiene. In the later years, the appearance of Landfill Leachate and Mudflat created diversity; this suggests that the field of water environmental studies expanded from fundamental issues that were already well studied to new and varied issues. The major Vision in the period of high economic growth was Industry-related, and this later expanded to Low-Carbon and Resource Recycling, which reflected the abovementioned global efforts.

\section{Discussion}

This study quantitatively analyzed Japanese academic activity related to the water environment during the years 1961-2010, using information extracted from the papers published in a domestic journal. We argued that the past 50 years of Japan's history of the water environment can be divided into three periods, namely period I (1961-1970), period II (1971-1995), and period III (1996-2010), based on the analysis. The relationship between academic activities and socioeconomic circumstances varied across the periods. During period I, academic activities reflected the strong public concern about industrial pollution, which may have pushed the enactment of legislations in 1970. During period II, academic activities were pursued concurrently with legislative control towards a solution for eutrophication. During period III, academic activities reflected not only domestic law, but also global concerns about climate change, biological diversity, and resource recycling. The results obtained in the present analysis were different to those obtained from studies of environmental innovation using patent data $[18,20]$, which suggested that the domestic regulatory pressure induced the activities of inventors. Trends in academic activities that occasionally preceded the legislations might have been attributed to the voluntary efforts of academic researchers to contribute to current societal issues. Further comprehensive analysis is necessary to clarify the causal associations among public concern, academic activity, governmental action, and innovation.

In this study, we also evaluated the diversification of academic research, which revealed that Visions and Target Water of the academic research were diversified over the 50-year period. In recent years, the Japanese water environment has improved, and serious problems related to health and economic damage have been rare. This could result in the loss of academic research in the relevant fields. In fact, articles classified as Industry-Related, Public Facilities-Related, and Water Environment Preservation clearly decreased after 1986. On the other hand, water-related global environmental issues, such as climate change and resource conservation, have become more pressing than local issues in Japan. However, we noted that in the journal Yosui-to-haisui, the proportion of articles about global issues did not seem to be large in comparison to those about industrial pollution in the 1960s or 
eutrophication in the years 1971-1995, thereby leading to the diversification of Visions and Target Water of the research. This diversification primarily meant the expansion of the field of water environmental studies from pollution issues to emerging global environmental issues. Another possible reason for this could have been that reports dealing with global issues are not necessarily submitted to domestic journals, thereby suggesting the limitation in the methodology that targeted a specific domestic journal for the survey. Therefore, analysis of papers in international journals would provide us with evidence to improve our understanding of the present global trend in research; this will be our next step of future study.

Finally, though we showed Japan effectively shifted research focuses by reflecting societal needs, it is yet unclear whether other countries are able to do so. The Japanese history in the past 50 years can be regarded as a showcase of a relationship between societal development and the environment. The end of an issue (e.g., industrial pollution) has made a next issue (e.g., eutrophication) visible along with a development of scientific knowledge, which allowed Japanese society to take action to them sequentially. However, the present situation of developing countries is different from the past situation of Japan. They are facing all types of issues simultaneously, namely industrial pollution, eutrophication, and global environmental issues because the problems are already scientifically visible from the experiences in developed countries. This difference inevitably causes inadequate resource allocation to cope with each of the issues. Therefore, adoptions of policies and regulations may not be sufficient in the present developing countries. Economic, technical, and human resource supports are essential for the immediate improvement of the environmental situation.

\section{Conclusions}

As a basis for a better understanding of the process of innovation related to the water environment, this study analyzed the historical trend of academic research activity in Japan for a 50-year period beginning in the 1960s. We employed a quantitative literature review and statistical analysis.

From the analysis, the following general trends for research related to the water environment in Japan were found. Many studies in the 1960s dealt with heavy metal pollution that originated with industries or with the treatment of human waste. During the 1970s, 1980s, and the mid-1990s, the research focus then shifted to the eutrophication of closed bodies of water. Then, from the mid-1990s and continuing through 2010, an increasing amount of research was directed toward reducing carbon and resource-recycling issues. This trend seems to be correlated with the societal background rather than with the environmental policies in Japan. The shift of issues coincided with the development of scientific knowledge about the issues in Japan. The situation is different for the present developing countries that are required to deal with all issues simultaneously because the accumulated knowledge makes already the issues scientifically visible.

We also found that after solving serious problems, such as water pollution from industries and eutrophication, indeed led to a diversification of research themes, including considering landfill leachate and mudflats. We argue, however, that such shifts are not directly attributed to changes in the vision of the research, but are instead due to the addition of new visions and perspectives to persistent fundamental issues, such as public hygiene.

As an area of future study, these results should be combined with other approaches, such as surveys of newspaper archives, a database of governmental subsidies, and a patent database in order to better understanding public concern, governmental action, and industrial activity, respectively, which are important factors in the process of innovation.

Supplementary Materials: The following is available online at http:/ /www.mdpi.com/2073-4441/10/10/1456/ s1, Table S1: Database constructed in this study.

Author Contributions: Conceptualization, M.K., K.H., M.U. and M.I.; Formal analysis, M.K.; Investigation, M.K. and M.T.; Methodology, M.K., K.H., M.T. and M.U.; Project administration, M.K.; Supervision, M.I.; Visualization, M.K.; Writing—original draft, M.K.; Writing—review \& editing, M.K., K.H., M.T., M.U. and M.I.

Funding: This work was partially supported by the Kurita Water and Environment Foundation (No. 14C024). 
Acknowledgments: We are grateful to Naoyuki Akiyama, Kosuke Sakai, Yoshiyuki Hachiya, and Hiroshi Hamada for their cooperation with the manual survey of journals.

Conflicts of Interest: The authors declare no conflict of interest. The founding sponsors had no role in the design of the study; in the collection, analyses, or interpretation of data; in the writing of the manuscript, and in the decision to publish the results.

\section{References}

1. Ministry of the Environment. Annual Report on the Environment, the Sound Material-Cycle Society and the Biodiversity in Japan, 2015. Available online: http:/ / www.env.go.jp/policy/hakusyo/past_index.html (accessed on 16 May 2018). (In Japanese)

2. Ministry of the Environment. Quality of the environment in Japan, 1994. Available online: http:/ / www.env. go.jp/en/wpaper/1994/index.html (accessed on 4 January 2017).

3. Okada, M.; Peterson, S.A. Water Pollution Control Policy and Management: The Japanese Experience; Gyosei Publishers: Tokyo, Japan, 2000.

4. Harada, M. Minamata disease: Methylmercury poisoning in Japan caused by environmental pollution. Crit. Rev. Toxicol. 1995, 25, 1-24. [CrossRef] [PubMed]

5. Nordberg, G.F. Cadmium and health in the 21st Century-Historical remarks and trends for the future. BioMetals 2004, 17, 485-489. [CrossRef] [PubMed]

6. Imai, I.; Yamaguchi, M.; Hori, Y. Eutrophication and occurrences of harmful algal blooms in the Seto Inland Sea, Japan. Plank. Benth. Res. 2006, 1, 71-84. [CrossRef]

7. Bai, X.; Imura, H. A comparative study of urban environment in East Asia: Stage model of urban environmental evolution. Int. Rev. Environ. Strategy 2000, 1, 135-158. [CrossRef]

8. Hara, K. Groundwater contamination and quality management policy in Asia. Int. Rev. Environ. Strategy 2006, 6, 291-306.

9. Kathuria, V. Controlling water pollution in developing and transition countries: Lessons from three successful cases. J. Environ. Manag. 2006, 78, 405-426. [CrossRef] [PubMed]

10. Ministry of the Environment. Annual Report on the Environment in Japan, 1969-2006. Available online: http:/ / www.env.go.jp/policy/hakusyo/past_index.html (accessed on 16 May 2018). (In Japanese)

11. Ministry of the Environment. Annual Report on the Environment and the Sound Material-Cycle Society in Japan, 2007-2008. Available online: http:/ / www.env.go.jp/policy/hakusyo/past_index.html (accessed on 16 May 2018). (In Japanese)

12. Ministry of the Environment. Annual Report on the Environment, the Sound Material-Cycle Society and the Biodiversity in Japan, 2009-2011. Available online: http:/ / www.env.go.jp/policy/hakusyo/past_index.html (accessed on 16 May 2018). (In Japanese)

13. Ui, J. Industrial Pollution in Japan; United Nations University Press: Tokyo, Japan, 1992.

14. Matsuo, T. Japanese experiences of environmental management. Water Sci. Technol. 2003, 47, 7-14. [CrossRef] [PubMed]

15. Kataoka, Y. Water quality management in Japan: Recent developments and challenges for integration. Environ. Policy Gov. 2011, 21, 338-350. [CrossRef]

16. Lanjouw, J.O.; Mody, A. Innovation and the international diffusion of environmentally responsive technology. Res. Policy 1996, 25, 549-571. [CrossRef]

17. Marinova, D.; McAleer, M. Environmental technology strengths: International rankings based on US patent data. In Center for International Research on the Japanese Economy Discussion Papers; University of Tokyo: Tokyo, Japan, 2003.

18. Popp, D. International innovation and diffusion of air pollution control technologies: The effects of $\mathrm{NO}_{\mathrm{x}}$ and $\mathrm{SO}_{2}$ regulation in the US, Japan, and Germany. J. Environ. Econ. Manag. 2006, 51, 46-71. [CrossRef]

19. Popp, D.; Newell, R.G.; Jaffe, A.B. Energy, the environment, and technological change. In Handbook of the Economics of Innovation; Hall, B.H., Rosenberg, N., Eds.; Elsevier: Amsterdam, The Netherlands, 2010; Volume 2, pp. 873-937.

20. Yabar, H.; Uwasu, M.; Hara, K. Tracking environmental innovations and policy regulations in Japan: Case studies on dioxin emissions and electric home appliances recycling. J. Clean. Prod. 2013, 44, 152-158. [CrossRef] 
21. Hara, K.; Kuroda, M.; Yabar, H.; Kimura, M.; Uwasu, M. Historical development of wastewater and sewage sludge treatment technologies in Japan-An analysis of patent data from the past 50 years. Environ. Dev. 2016, 19, 59-69. [CrossRef]

22. Hascic, I.; de Vries, F.; Johnstone, N.; Medhi, N. Effects of environmental policy on the type of innovation: The case of automotive emission-control technologies. OECD J. Econ. Stud. 2008, 2009, 1-18. [CrossRef]

23. Johnstone, N.; Haščič, I.; Popp, D. Renewable energy policies and technological innovation: Evidence based on patent counts. Environ. Resour. Econ. 2010, 45, 133-155. [CrossRef]

24. Johnstone, N.; Haščič, I.; Poirier, J.; Hemar, M.; Michel, C. Environmental policy stringency and technological innovation: Evidence from survey data and patent counts. Appl. Econ. 2012, 44, 2157-2170. [CrossRef]

25. Wang, M.-H.; Yu, T.-C.; Ho, Y.-S. A bibliometric analysis of the performance of water research. Scientometrics 2010, 84, 813-820. [CrossRef]

26. Hu, J.; Ma, Y.; Zhang, L.; Gan, F.; Ho, Y.-S. A historical review and bibliometric analysis of research on lead in drinking water field from 1991 to 2007. Sci. Total Environ. 2010, 408, 1738-1744. [CrossRef] [PubMed]

27. Klewitz, J.; Hansen, E.G. Sustainability-oriented innovation of SMEs: A systematic review. J. Clean. Prod. 2014, 65, 57-75. [CrossRef]

28. Wold, S. Principal component analysis. Chemometr. Intell. Lab. 1987, 2, 37-52. [CrossRef]

29. Gabriel, K.R. The biplot graphic display of matrices with application to principal component analysis. Biometrika 1971, 58, 453-467. [CrossRef]

30. Shannon, C.E. A mathematical theory of communication. Bell Syst. Tech. J. 1948, 27, 379-423. [CrossRef]

31. Hammer, Ø.; Harper, D.A.T.; Ryan, P.D. PAST: Paleontological statistics software package for education and data analysis. Palaeontol. Electron. 2001, 4, 1-9.

32. United Nations. United Nations Conference on Environment and Development, 1997. Available online: http:/ / www.un.org/geninfo/bp/enviro.html (accessed on 16 May 2018).

33. Ministry of the Environment. Annual Report on the Environment, the Sound Material-Cycle Society and the Biodiversity in Japan, 2013. Available online: http:/ / www.env.go.jp/policy/hakusyo/past_index.html (accessed on 16 May 2018). (In Japanese)

(C) 2018 by the authors. Licensee MDPI, Basel, Switzerland. This article is an open access article distributed under the terms and conditions of the Creative Commons Attribution (CC BY) license (http:/ / creativecommons.org/licenses/by/4.0/). 